\title{
As Causas Incidentais nos Processos de Declaração de Nulidade Matrimonial segundo a Instrução "Dignitas Conubii"1
}

\author{
Dr. Pe. João Carlos Orsi
}

RESUMO

O texto trata da causa incidental de modo genérico, e considera o modo de ser proposta, perante quem deve ser proposta, a sua admissão ou rejeição, e quando pode ser proposta. Considerando, todavia, que a Instrução Dignitas Connubii legisla de modo detalhado sobre esse assunto, tratamos de confrontar as normas codiciais com as novidades apresentadas pela Instrução.

Palavras chaves: Instrução, Dignitas Connubii, causa, causa incidental, questão principal, questão incidental, juízo principal, colégio, defensor do vínculo, decreto, decreto decisório, sentença, apelação, exceção.
ABSTRACT

The text deals with incidental cause in generic way, and takes into account the way its proposed, before the one who suppose to be proposed, its admition or rejection, and when can be proposed. Therefore, considering that the instruction Dignitas Connubii, lagislate in detailed way this issue, we confront the rule codes with the new issues presented by the Instruction.

Key-words: Instruction, Dignitas Connubii, incidental cause, main question, incidental question, main judgement, college, link defender, decree, finaly decree, sentence, appealing, exception.

Pontifício Conselho para os textos legislativos, "Dignitas Connubii", Instrução que devem observar os tribunais diocesanos e interdiocesanos ao tratarem as causas de nulidade matrimônio, Paulinas, 2005. 


\section{INTRODUÇÃO}

A causa incidental pode ser utilizada em qualquer tipo de causa, inclusive nas matrimoniais.

A Instrução "Dignitas Connubii" (doravante Instrução) trata este assunto detalhadamente, inclusive acrescentando e modificando as normas codiciais vigentes sobre o mesmo.

A finalidade deste trabalho é cotejar as normas codiciais com as da Instrução numa tentativa de verificar qual o "iter" processual mais adequado para as causas incidentes, quando ocorrerem, no processo matrimonial canônico. Esta tentativa é necessária uma vez que “... permanecem totalmente em vigor as leis processuais do Código de Direito Canônico para a declaração de nulidade do matrimônio, que se deverão sempre tomar como referência para interpretar a Instrução"2. É uma tentativa de adequar a Instrução com a lei canônica ora vigente, e que constitui, ordinariamente, a fonte e o critério maior de interpretação da Instrução.

Considerando que, a Instrução foi especificamente "elaborada e publicada para servir de ajuda aos juízes e aos outros ministros dos tribunais eclesiásticos" ${ }^{3}$, a suas normas se aplicam direta e principalmente ao processo ordinário de declaração de nulidade matrimonial, e não serve, portanto, de fonte e nem de parâmetro aplicativo para os demais processos canônicos. Para as demais causas se aplicam "in totum" as normas codiciais.

\section{CAUSAS INCIDENTAIS "IN GENERE”}

O conceito de causa incidental se encontra no cân. 1587 que estabelece: "Dá-se uma causa incidente sempre que, depois de começado o juízo mediante a citação, se propõe uma questão que, embora não contida expressamente no libelo de introdução da lide, é de tal modo pertinente à causa, que geralmente deve ser resolvida antes da questão principal."4

2 Instrução "Dignitas Connubii”, Introdução, p. 17.

3 Idem, ibidem.

4 "Causa incidens habetur, quoties, incepto per citationem iudicio, quaestio proponitur quae, tametsi libello, quo lis introducitur, non contineatur expresse, nihilominus ita ad causam pertinet ut resolvi plerumque debeat ante quaestionem principalem." 
Durante o desenvolvimento do processo, podem levantar-se diversas questões controversas que, não se encontrando contidas na demanda, conservam uma relação com a questão principal, reclamando para si uma decisão judicial. Quando se torna necessária uma proposição da questão num processo diferenciado para tratar de resolvê-la, estamos na presença de um incidente ou causa incidental. Se a questão incidental não requerer essa proposição à parte - por se poder resolver juntamente com a questão principal na sentença definitiva - não se produzirá propriamente uma causa incidental (cf. cân. 1589, § 2).

A característica da ação incidental é que deve ser resolvida antes da questão principal, dado o caráter prejudicial que sempre revestem as questões incidentais. Podem propor questões incidentais as partes processuais, públicas ou privadas, o juiz ou um terceiro (cf. cânones 1596 - 1597), embora haja que ter em conta a natureza da questão levantada para que possa verificar-se esta última hipótese.

O cânon deixa claro que a ação incidental só pode ser proposta "depois de começado o juízo mediante a citação". Aqui, e com o que determina o cân. 1517 , se percebe que há uma grande coerência com o cân. $1512,5^{\circ}$, que estabelece que o início do juízo e a primeira instância se iniciam com a citação.

Também se apresentam como causa incidental algumas exceções que não são verdadeiramente causas incidentais, porque são questões que podem se originar antes citação, como por exemplo, a argüição sobre a competência do juiz, o recurso contra a rejeição do libelo, etc.

Em relação ao processo matrimonial, o art. 218 da Instrução apresenta dois princípios: o primeiro é que "nas causas de declaração de nulidade matrimonial, considerada a natureza da causa principal, as questões incidentais não devem ser propostas nem admitidas com ligeireza"5. O segundo é que "se forem admitidas, devem ser resolvidas com particular diligência e com a máxima rapidez"6. Os dois princípios são realmente importantes para a melhor tramitação da causa, evitando dilações inúteis. Às vezes, as causas incidentais se apresentam com a finalidade de dilatar o processo. Os dois princípios visam suprimir esses excessos. O primeiro princípio se dirige às

\footnotetext{
5 "In causis nullitatis matrimonii quaestiones incidentales, attenta natura causae principalis, leviter ne proponantur nec admittantur...".

6 "... quod si admittantur peculiari sollicitudine quam citius definiendae sunt"
} 
partes para que não proponham estas causas com excessiva facilidade e ao juiz para que não a admita.

O artigo menciona a Alocução do Papa João Paulo II aos Auditores da Rota Romana, no dia 22 de janeiro de 1996. O Santo Padre afirma: "4. Mai, tuttavia, dovrà dimenticarsi che si tratta di un bene indisponibile e che finalità suprema è l'accertamento di una verità oggettiva, che tocca anche il bene pubblico. In questa prospettiva, atti processuali quali la proposizione di certe "questioni incidentali", o comportamenti moratori, estranei, ininfluenti o che addirittura impediscono il raggiungimento di detto fine, non possono essere ammessi nel giudizio canonico".

\section{COMO SE PROPÕE E PERANTE QUEM SE PROPÕE A CAUSA INCIDENTAL}

O cân. 1588 estabelece: "A causa incidente se propõe por escrito ou oralmente, perante o juiz competente para definir a causa principal, indicando-se o nexo existente entre ela e a causa principal."

A questão incidental pode ser proposta por escrito ou oralmente. Neste segundo caso, o notário tomará por termo.

Segundo o cânon, para que causa incidental seja admitida é necessário que esta tenha um nexo ou vinculação com a causa principal. Nas causas de declaração de nulidade de matrimônio, existe este vínculo quando a parte demandada recusa ou pede a exclusão de uma ou de todas as testemunhas.

O art. 220 da Instrução determina que "Se o pedido não for pertinente à causa ou se revelar evidentemente destituído de todo fundamento, o presidente ou o relator deve rejeitá-la in limine, sem prejuízo do disposto no art. $221 " 8$.

O art. 221 da Instrução explica o que se deve fazer no caso em que a parte interessada ou o defensor do vínculo interponham recurso diante do colégio contra um decreto de mero expediente emitido pelo relator, o

7 "Causa incidens proponitur scripto vel ore, indicato nexu qui intercedit inter ipsam et causam principalem, coram iudice competenti ad causam principalem definiendam."

8 "Si petitio non pertineat ad causam vel evidenter omni fundamento destitute appareat, potest praeses vel ponens eam in limine, salvo art. 221" 
presidente ou o auditor, para a tramitação da causa principal. O recurso deve ser interposto no prazo de 10 dias da notificação do decreto; "do contrário, se presume que as partes e o defensor do vínculo tenham aceitado o decreto"'.

O § 2 do art. 221 determina que "o recurso deve ser apresentado ao próprio autor do decreto, o qual, a não ser que julgue dever revogá-lo, deve transmiti-lo sem demora ao colégio"10. Quem emitiu o decreto pode revogá-lo antes do recurso, mas se o mantém, deve submetê-lo ao colégio. De fato, o recurso deve ser interposto diante do colégio, ainda que seja apresentado ao juiz autor do decreto.

\section{ADMISSÃO OU REJEIÇÃO DA CAUSA INCIDENTAL}

\section{O art. 222 da Instrução estabelece:}

"§ 1 O colégio, recebida a petição e tendo ouvido o defensor do vínculo e as partes, decida se a questão incidental proposta parece ter fundamento e conexão com o juízo principal, ou se, pelo contrário, deve ser rejeitada liminarmente; e, no caso de admiti-la, se deve ser resolvida observando integralmente a forma do juízo, portanto, com prévia formulação das dúvidas, ou através de memoriais e, finalmente, por decreto".

"§ 2 Os trâmites previstos no $\S 1$ devem ser executados com a maior rapidez, ou seja, com a exclusão de qualquer apelação ou recurso e sem demora"11.

Segundo o $\S 1$ a primeira atitude do colégio é ouvir o defensor do vínculo e as partes. Após, pode tomar duas atitudes: A primeira, decidir se a questão incidental tem conexão com o juízo principal, ou, pelo contrário, deve ser rejeitada liminarmente.

9 "... secus partes et defensor vinculi decreto acquievisse censentur".

10 "Recursus coram ipso decreti auctore proponendus est; qui tamen illum, nisi dcretum a se latum revocandum censuerit, sine mora collegio deferre debet".

$11 \S 1$. Collegium, recepta petitione et auditis defensore vinculi ac partibus, decerneat utrum proposita incidens quaestio fundamentum ac nexum cum principali iudicio habere videatur, an vero sit in limine reicienda; et, si eam admittat, utrum eadem solvi debeat integra iudicii forma servata, ideoque cum dubiorum propositione, an per memorialia et denique per decretum". $\S 2$. Quae in § 1. praescribuntur, expeditissime, id est exclusa quavia appellatione et remoto quovis recursu, sine mora perficienda sunt". 
A segunda, é se for admitida, a questão deve ser resolvida observando integralmente a forma do juízo, isto é, com a formulação da dúvida, ou através de memoriais, e, finalmente, por decreto.

A rapidez a que se refere o $\S 2$ significa a exclusão de qualquer apelação ou recurso. Tendo o colégio decidido sobre a causa incidental, desta não se admite apelação.

O art. 223 da Instrução se refere à intervenção do promotor de justiça. Podem solicitá-la "a parte o defensor do vínculo como "ex officio". O critério para a solicitação dessa intervenção é "a natureza ou a dificuldade da questão incidental”.

\section{NORMAIS FUNDAMENTAIS}

Há um duplo procedimento para se resolver as causas incidentais, isto é, através de sentença do colégio, ou por decreto motivado.

Segundo o art. 224, § 1 da Instrução, "Se a questão incidental tiver de resolver-se por sentença do colégio, observem-se os câns. 1658 - 1670 relativos ao processo contencioso oral, a não ser que, dada a gravidade do caso, outro seja o parecer do colégio"12.

O art. 224, § 1 se refere explicitamente ao cân. 1590, § 1 que determina: "Se a questão incidente deve ser resolvida por sentença, observem-se as normas relativas ao processo contencioso oral, a não ser que outro seja 0 parecer do juiz, dada a importância da questão."13

Se o incidente se deve resolver mediante sentença do colégio, o trâmite que se deve seguir na causa incidental é o do processo contencioso oral (cf. cânones 1656 ss.). Com essa disposição, o legislador pretende dar maior rapidez às causas incidentais, de modo que não se prolongue por demasiado tempo a causa principal. Deve-se observar que podem levantarse questões incidentais de tal envergadura que requeiram um tratamento segundo as vias do contencioso ordinário; por exemplo, naqueles supostos

12 "Si quaestio incidens solvi debeat per sententiam collegii, serventur cann. 1658 - 1570 de processu contentioso orali, nisi, attenta rei gravitate, aliud collegio videatur"

13 "§ 1. Si quaestio incidens solvi debeat per sententiam, serventur normae de processu contentioso orali, nisi, attenta rei gravitate, aliud iudici videatur." 
em que surge como incidental uma causa excluída pelo direito (cân. 1656), como acontece com as causas de nulidade matrimonial (cân. 1690).

O § 2 do art. 224 da Instrução estabelece a segunda forma pela qual se pode resolver a questão incidental, ou seja, através de decreto motivado. Determina o inciso que "o colégio, porém, por decreto devidamente fundamentado, para obter maior celeridade, pode derrogar as normas processuais, referidas no $\S 1$, que não sejam exigidas para a validade, salvaguardada a justiça"14

Esta norma repete o que o cân. 1670 havia estabelecido para os processos orais.

O art. 225 da Instrução estabelece como se deve agir para se resolver a questão por meio de decreto motivado. Completa o cân. 1590, § 2 que afirma: "Devendo, porém, ser resolvida por decreto, o tribunal pode confiar a questão a um auditor ou ao presidente." 15

O artigo mencionado acrescenta: "Se, porém, a questão houver de ser resolvida por decreto, deve fixar-se quanto antes, para as partes e ao defensor do vínculo, um prazo para que apresentem num breve texto escrito ou memorial as suas razões; todavia, o colégio pode atribuí-la ao auditor ou ao presidente, a não ser que a própria natureza da causa ou outras razões aconselhem claramente a agir de outro modo"16.

O cân. 1591 prescreve que "Antes da conclusão da causa principal, havendo justa causa, pode o juiz ou o tribunal revogar ou reformar o decreto ou sentença interlocutória, a requerimento de uma das partes ou "ex officio", ouvidas as partes" 17

14 "§2. Collegium autem potest suo decreto, motivis praedito, normis processualibus, de quibus in $\S 1$, quae non sint ad validitatem statutae, derogare, ut celeritati, salva iustitia, consulat".

15 "§ 2. Si vero solvi debeat per decretum, tribunal potest rem committere auditori vel praesidi."

16 "Si vero quaestio solvi debeat per decretum, partibus et vinculi defensori quam citius terminus assignandus est, in quo suas rationes afferant per breve scriptum seu memorale; potest aut collegium, nisi aliud pateat aut ex rei natura requiratur, rem auditori vel praesidi committere".

17 "Antequam finiatur causa principalis, iudex vel tribunal potest decretum vel sententiam interlocutoriam, iusta intercedente ratione, revocare aut reformare, sive ad partis instantiam, sive ex officio, auditis partibus." 
O art. 226 da Instrução acrescenta que também o defensor do vínculo pode pedir que se revogue a sentença interlocutória. E, quanto ao ouvir as partes, o artigo acrescenta que se ouça o defensor do vínculo. $\mathrm{O}$ artigo coloca uma exceção, segundo a qual, não se pode reformar a sentença interlocutória, quando se trata "de uma decisão com força de sentença definitiva".

O decreto decisório deve ser motivado, conforme determina o cânon 1617.

O art. 228 da Instrução determina que "não se dá apelação contra decisão que define causa incidente que não tenha força de sentença definitiva, a não ser que se acumule com a apelação da sentença definitiva" (cf. cân. 1629, n.4) ${ }^{18}$.

A sentença interlocutória ou decreto, quando tem força de sentença definitiva (cf. art. 226), nesse caso será susceptível de apelação independente (cf. cân. 1618, em conexão com o cân. 1629, $4^{\circ}$ ).

O art. 227 da Instrução prescreve que "se um juiz único tratar da causa, ele mesmo examinará as questões incidentais, com as devidas adaptações" 19 .

\section{QUANDO SE PODE PROPOR A CAUSA INCIDENTAL}

A causa incidental pode ser proposta em qualquer tempo, antes da litiscontestação ou na própria litiscontestação.

A causa incidental pode ser proposta em qualquer tempo, pois o cân. 1459, $\S 1$ estabelece: “§ 1 . Vícios dos quais possa derivar a nulidade da sentença podem ser excetuados em qualquer estado ou grau do juizo ou também e também ser declarados ex officio pelo juiz."20

Esta prescrição vale principalmente em relação aos vícios que tornam nula a sentença por vício insanável, como por exemplo, o da incompetência absoluta ou da negação do direito de defesa (cf. cân. 1620, $1^{\circ}$ e $7^{\circ}$ ).

18 "non datur appellatio a decisione qua causa incidens definitur, quae non habet vim sententiae definitivae, nisi cumuletur cum appellatione a sententia definitive (cf. can. 1629, n. 4)".

19 "Quod si iudex unicus causam cognoscat, ipse, congrua congruis referendo, de quaestionibus incidentibus videt".

20 "§ 1. Vitia, quibus sententiae nullitas haberi potest, in quolibet iudicii statu vel gradu excipi possunt itemque a iudice ex officio declarari." 
Contra esses vícios que invalidam a sentença por vício insanável, as partes podem mover ação ou exceção de nulidade; o juiz pode, ex officio, declará-la em qualquer fase ou grau do juízo. A razão é óbvia: por exigências do princípio de economia processual, pois a jurisdição não é para ser exercida inutilmente.

A causa incidental pode ser proposta antes da litiscontestação, pois o cân. 1459, § 2 estabelece: "§ 2: Além dos casos mencionados no $\S 1$, as exceções dilatórias, principalmente as que se referem às pessoas e ao modo do juízo ${ }^{21}$, devem ser propostas antes da litiscontestação, a não ser que surjam depois dela, e definidas quanto antes."22

As exceções dilatórias devem ser propostas "in limine litis", antes de contestar a demanda, principalmente às relativas às pessoas e ao modo do juízo, a não ser que surjam depois da litiscontestação.

Entre as exceções relativas às pessoas se incluem as exceções de incompetência absoluta ou relativa, ou de suspeita contra o juiz. Entre as relativas ao modo do juízo, se se incluem as exceções referentes ao uso ilegítimo do processo documental (cf. cân. 1686, ou do processo contencioso oral (cf. cân. 1690).

Estas exceções devem ser julgadas com a antecedência possível: "quam primum" (quanto antes). Foi escolhida essa expressão e não a expressao "statim" (imediatamente), porque, às vezes, o juiz necessita de examinar os autos e certificar-se dos fatos antes de decidir acerca da exceção proposta.

Contestada a demanda, fica incluído normalmente o tempo hábil para propor a exceção.

Propor a exceção é facultativo, pois quem tem o direito a defender-se pode deixar de fazê-lo. Nesse caso se presume que renuncia a opor as exceções dilatórias correspondentes.

21 Exceção é uma alegação tendente a excluir a ação proposta pelo demandante. Pode ser dilatória, se tende a diferir a ação; peremptória, se tende eliminá-la radicalmente. Ambas podem ser substanciais (quando se referem ao objeto da controvérsia) ou processuais (se dizem respeito às pessoas que intervém no juízo ou as suas atuações no mesmo).

22 "§ 2. Praeter casus de quibus in $\S 1$, exceptiones dilatoriae, eae praesertim quae respiciunt personas et modum iudicii, proponendae sunt ante contestationem litis, nisi contestata iam lite emerserint, et quam primum definiendae." 
Mas a presunção de renúncia dilatória deixa de existir onde não se pode renunciar, como por exemplo, a não oposição à ação matrimonial ou à ação de nulidade de ordenação, ou à exceção de incompetência absoluta (cf. cân. 1461). Contra essas pode opor exceção o defensor do vínculo ou o promotor de justiça nas causas relativas ao bem público, ou o próprio juiz agindo "ex officio", suprindo o demandado ou a defesa pública, quando estes não se contraponham.

Ainda antes da litiscontestação estabelece o cân. 1464: "Questões de caução pelas despesas judiciais, de concessão de gratuito patrocínio, pedido logo desde o início, e outras semelhantes, devem regularmente ser julgadas antes da litiscontestação."23

Este cânon determina que o juiz deva, antes da litiscontestação, tratar de duas coisas, se tiverem sido pedidas, logo no início da ação, isto é, questões de caução pelas despesas judiciais e da concessão do gratuito patrocínio.

A prestação de caução pelas despesas judiciais é um meio ou medida eficaz para garantir o pagamento das despesas. O direito a esta caução é suposto pelo cân. $1649, \S 1,5^{\circ}$. A administração da justiça é de si gratuita nos tribunais eclesiásticos, o que não impede de quem litigue, se não é considerado legalmente como pobre, satisfaça as despesas e as custas do juízo. Supondo que, no fim do juízo, o vencido não tenha o menor desejo de pagar as custas, e que não é espírito da lgreja adotar meios coativos para exigir o pagamento das custas, é razoável e prudente a medida do depósito. Não é preciso que se faça o depósito de uma só vez, de toda a quantia prevista, mas pode ser prudente exigir o depósito por partes ${ }^{24}$.

Deve efetuar o depósito quem pede as atuações. As que o juiz pratica "ex officio", é natural que pertença satisfazê-las o autor. A antecipação de caução não julga antecipadamente a quem a seu tempo serão impostas às custas.

23 "Quaestiones de cautione pro expensis iudicialibus praestanda aut de concessione gratuiti patrocinii, quod statim ab initio postulatum fuerit, et aliae huiusmodi regulariter videndae sunt ante litis contestationem."

24 A "Provida Mater", no art. 235, § 1, estabelecia: "Ut prospiciatur expensis iudicialibus, peritorum honorariis, si peritiae fiat locus, necnon testium indemnitati, praeses decernere potest ut congrua pecunia deponatur in arca tribunalis: quae sane pecunia, lite pendente, si id praesidi videatur, augenda erit." 
Em relação estreita com a prestação de caução, acha-se a questão da isenção total ou parcial de despesas da lide. Costuma chamar-se gratuito patrocínio tanto à isenção total como à parcial, ou redução de custas.

São os juízes a autoridade competente para as questões que surjam sobre depósito de caução ou patrocínio gratuito nos tribunais eclesiásticos. Deve-se designar "ex officio" procurador e advogado em favor de quem é concedida isenção ou redução de custas.

Tanto as questões de caução pelas despesas judiciais, de concessão de gratuito patrocínio, e outras semelhantes, se são pedidas no início do juízo, devem ser julgadas e resolvidas habitualmente antes da contestação da lide. Diz o cânon "regulariter", porque, muitas vezes, surgem estes incidentes no meio e no fim do juízo, e então é lógico que sejam resolvidas quando surgem, por exemplo, a pobreza legal sobrevinda, à designação de advogado.

A causa incidental pode também ser proposta na própria litiscontestação. O cân. 1462, § 2 estabelece: "Outras exceções peremptórias sejam propostas na litiscontestação e devem ser tratadas a seu tempo, segundo as regras relativas às questões incidentes." 25

As exceções peremptórias são aquelas que anulam ou extinguem a ação, ou impedem para sempre o seu exercício.

Quando o cânon fala de "outras exceções peremptórias", se refere às exceções peremptórias "litis non finitae", porque as exceções peremptórias de "litis finitae" são tratadas no $\S 1$, do cânon.

Omitimos as exceções peremptórias "litis finitae", como por exemplo, de coisa julgada (cf. cân. 1462, § 1) que não se aplica nas causas sobre o estado das pessoas, como são as causas de nulidade matrimonial (cf. cân. 1643).

As exceções peremptórias "litis non finitae" devem ser tratadas conforme as regras para as causas incidentais.

25 "§ 2. Aliae exceptiones peremptoriae proponantur in contestatione litis, et suo tempore tractandae sunt secundum regulas circa quaestiones incidentes." 


\section{BIBLIOGRAFIA}

\section{Código de Direito Canônico}

Pontifício Conselho para os textos legislativos, "Dignitas Connubii", Instrução que devem observar os tribunais diocesanos e interdiocesanos ao tratarem as causas de nulidade matrimônio, Paulinas, 2005.

\section{Artigos}

Failde, Juan Jose Garcia, Análise da Instrução Dignitas Connubii, Forum Canonicum, Lisboa, vol. 1/1-2, Ano I, pp. 49 - 80, Janeiro / Dezembro 2006.

Heras, Feliciano Gil de las, Las pruebas, las causas incidentales, la publicación y la conclusión de la causa em la Instrucción Dignitas Connubii, Jus Canonicum, Pamplona, vol. XLVI, n. 91, pp. 177 - 206, Enero - Junio 2006.

\section{Pe. Dr. João Carlos Orsi}

Professor de Direito Canônico pelo Instituto de Direito Canônico "Pe. Dr. Giuseppe Benito Pegoraro" 